\title{
Current evidence for prosthesis selection: What can we really say?
}

\author{
From the Department of Cardiothoracic Surgery, Stanford University, Stanford, Calif. \\ Received for publication Nov 18, 2018; revisions received March 5, 2019; accepted for publication March 7 , \\ 2019; available ahead of print June 11, 2019. \\ Address for reprints: Y. Joseph Woo, MD, Department of Cardiothoracic Surgery, Stanford University, School of \\ Medicine, Falk Cardiovascular Research Building CV-235, 300 Pasteur Drive, Stanford, CA 94305-5407 \\ (E-mail: joswoo@stanford.edu). \\ J Thorac Cardiovasc Surg 2019;158:368-75 \\ $0022-5223 / \$ 36.00$ \\ Copyright (C) 2019 Published by Elsevier Inc. on behalf of The American Association for Thoracic Surgery \\ https://doi.org/10.1016/j.jtcvs.2019.03.094
}

Peter Chiu, MD, Andrew B. Goldstone, MD, PhD, Michael P. Fischbein, MD, PhD, and Y. Joseph Woo, MD
Deciding between a mechanical and a biologic valve prosthesis for valve replacement has been a perennial challenge for patients and surgeons alike. Although mechanical valve prostheses have a long track record of durability, these valves also require lifelong anticoagulation to prevent thromboembolic complications and thus carry a concomitant increased risk of bleeding. In contrast, biologic valve prostheses do not require long-term anticoagulation but have a higher incidence of reoperation for structural valve deterioration. Balancing these risks is a challenge that must be personalized to the individual patient.

\section{EARLY EFFORTS TO DEVELOP GUIDELINES}

The earliest efforts to evaluate the comparative effectiveness of mechanical and biologic valve prostheses were the Edinburgh Heart Valve Trial and the Veterans Affairs Cooperative Study on Valvular Heart Disease. ${ }^{1,2}$ In the Edinburgh Heart Valve Trial, patients undergoing aortic or mitral valve replacement were randomized to the BjorkShiley mechanical valve prosthesis (Shiley Inc, Irvine, Calif) or a biologic valve prosthesis, initially the Hancock porcine valve (Medtronic Inc, Minneapolis, Minn) and later the Carpentier-Edwards porcine valve (Edwards Lifesciences, Irvine, Calif). At 12 years, there was no difference in survival but an increased risk of reoperation among patients who received a biologic valve prosthesis $(8.5 \%$ vs $37.1 \%$, $P<.001){ }^{1}$ The Veterans Affairs Cooperative Study similarly randomized patients to the Bjork-Shiley mechanical heart valve or the Hancock porcine biologic prosthesis. Similar to the Edinburgh Heart Valve Trial, there was no difference in survival at 11 years, but there was an increased risk of structural valve failure with biologic prostheses compared with mechanical prostheses. Notably, there was a difference in the risk of structural valve deterioration for biologic valves depending on the implanted position with a $15 \%$ probability of structural valve failure for biologic prostheses in the aortic valve position at 11 years compared with a $36 \%$ probability in the mitral valve position. ${ }^{2}$ Both trials recommended that most patients undergoing mitral old.

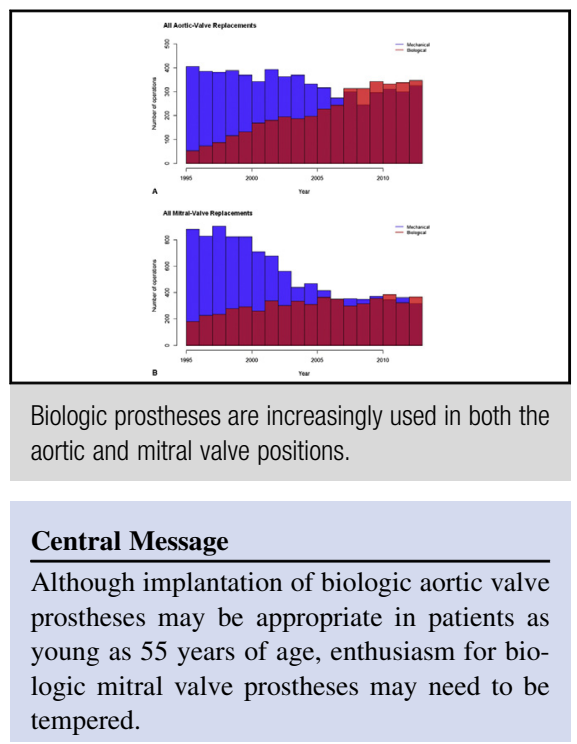

The Invited Expert Opinion provides a perspective on this topic based on the following paper: N Engl J Med. 2017;377:1847-57. DOI: 10 1056/NEJMoa1613792.

See Commentary on page 376 .

valve replacement and younger patients undergoing aortic valve replacement receive mechanical valve prostheses.

In the years after these 2 landmark trials, singleinstitution studies demonstrating adequate performance of biologic prostheses with low rates of reoperation were published. ${ }^{3,4}$ Together with the randomized data, these findings led to the publication of professional guidelines in 1998 containing a class IIa recommendation that patients aged 65 years or less receive mechanical valves in the aortic position and that patients aged 70 years or less receive mechanical valves in the mitral position (Table 1$){ }^{5}$ Further, a class IIb recommendation existed for biologic valve prostheses in either position for patients younger than 65 years

\section{EXPANDING USE OF BIOLOGICAL PROSTHESES IN THE AORTIC VALVE POSITION}

Subsequent publication of the long-term results arising from the Veterans Affairs Cooperative Study on Valvular Heart Disease and the Edinburgh Heart Valve Trial suggested that mechanical valve prosthesis implantation was 
associated with reduced risk of reoperation in both the aortic and mitral valve positions. ${ }^{6,7}$ However, these valves, having been implanted between 1975 and 1982, were no longer in use. Contemporary evidence arising from single-institution studies revealed a lower incidence of structural valve deterioration compared with the biologic valves used in these early trials, thereby introducing controversy regarding prosthesis selection. Subsequently, professional guidelines published in 2006 were amended to strengthen the recommendation for patients aged less than 65 years to receive biologic prostheses (IIa) in the setting of lifestyle considerations "after detailed discussions of the risks of anticoagulation versus the likelihood that a second [aortic valve replacement] may be necessary in the future" (Table 1). ${ }^{8}$

At this point, selection of a mechanical or biologic aortic valve prosthesis was considered "reasonable" (class IIa recommendation) for patients aged less than 65 years (Table 1). ${ }^{8}$ In New York State between 1997 and 2004, the proportion of biologic prostheses implanted in the aortic position increased from $15 \%$ to $74 \%$ among patients aged 50 to 70 years, and this was mirrored both in Sweden $(17 \%$ between 1997 and 2002 to $58 \%$ between 2006 and 2013) and California (12\% to 52\% between 1996 and 2013) for similarly aged patients ${ }^{9-11}$ (Figure 1, A). The seeming ambivalence of the guideline was effectively an endorsement of the increasingly aggressive implantation of biologic prostheses in younger patients.

In the years following, evidence demonstrating improved durability of biologic prostheses continued to be published. The University of Toronto reported in a retrospective series a $5.9 \%$ risk of reoperation at 15 years for patients aged 60 to 70 years. ${ }^{12}$ The Cleveland Clinic Foundation also reported their single-institution experience with a $5.1 \%$ risk of valve explantation for structural valve deterioration among patients aged 60 to 80 years. ${ }^{13}$ Furthermore, Stassano and colleagues ${ }^{14}$ randomized 310 patients aged 55 to 70 years to receive a biologic or mechanical prosthesis for aortic valve replacement. There was no difference in survival to 13 years after surgery $(P=.2)$, but there was a difference in the rate of reoperation $(0.62 \%$ /patient-year for mechanical prostheses vs $2.32 \% /$ patient-year for biologic prostheses, $P<.001)$. Together, these data were encouraging for the expanded use of biologic valve prostheses in younger patients.

\section{EXPANDING USE OF BIOLOGICAL PROSTHESES IN THE MITRAL VALVE POSITION}

Evidence similarly emerged that contemporary biologic valve prostheses in the mitral position were less prone to failure compared with the devices used in the randomized trials. Although the Veterans Affairs Cooperative Study reported $50 \%$ probability of mitral valve reoperation at 15 years, ${ }^{6}$ the second-generation Carpentier-Edwards PERIMOUNT valve experienced $95.2 \%$ freedom from structural valve deterioration at 10 years among patients aged 61 to 70 years compared with $75.2 \%$ for first- and second-generation devices $(P<.05)$, respectively. ${ }^{15}$ During this period, surgeons implanted an increasing number of biologic mitral valve prostheses in patients. In New York State, the proportion of biologic valve prostheses implanted increased from $8 \%$ to $60 \%$ between 1997 and 2012 for patients aged 50 to 70 years ${ }^{16}$; in the state of California, there was an increase from $17 \%$ to $54 \%$ between 1996 and 2013 among all age ranges (Figure 1, $B$ ).${ }^{11}$ The 2006 guidelines were subsequently amended to lower the age recommendation for reasonable use of a biologic mitral valve prosthesis to 65 years, the same as the aortic position (Table 1). ${ }^{8}$

\section{A BOLD STEP FORWARD?}

Single-center retrospective cohort studies suggested that contemporary valve prostheses might be superior to those implanted in early randomized controlled trials; however, the lack of a direct comparison was a significant limitation.

TABLE 1. Evolution of guidelines for prosthesis selection in valve replacement

\begin{tabular}{|c|c|c|c|c|c|c|c|c|}
\hline \multirow{3}{*}{ Bonow, $1998^{5}$} & \multicolumn{4}{|c|}{ AVR } & \multicolumn{4}{|c|}{ MVR } \\
\hline & \multicolumn{2}{|c|}{ Mechanical } & \multicolumn{2}{|c|}{ Biologic } & \multicolumn{2}{|c|}{ Mechanical } & \multicolumn{2}{|c|}{ Biologic } \\
\hline & $<65 \mathrm{y}$ & IIa & $\geq 65 \mathrm{y}$ & I & $\leq 70 \mathrm{y}$ & IIa & $>70 y$ & IIa \\
\hline & & & $<65 \mathrm{y}$ & $\mathrm{IIb}$ & & & $<65 \mathrm{y}$ & $\mathrm{IIb}$ \\
\hline & & \multicolumn{3}{|c|}{ Mechanical } & & \multicolumn{3}{|c|}{ Biologic } \\
\hline \multirow[t]{2}{*}{ Bonow, $2006^{8}$} & & $<65$ & & IIa & & $\geq 65 y$ & & IIa \\
\hline & & & & & & $<65 \mathrm{y}^{*}$ & & IIa \\
\hline \multirow[t]{2}{*}{ Bonow, $2008^{45}$} & & $<65$ & & IIa & & $\geq 65 y$ & & IIa \\
\hline & & & & & & $<65 y^{*}$ & & IIa \\
\hline Nishimura, $2014^{18}$ & & $<60$ & & IIa & & $>70 y$ & & IIa \\
\hline Nishimura, $2017^{19}$ & & $<50$ & & IIa & & $>70 y$ & & IIa \\
\hline
\end{tabular}

$A V R$, Aortic valve replacement; $M V R$, mitral valve replacement. *For lifestyle considerations after detailed discussions of the risks of anticoagulation versus the likelihood of a second valve replacement. 


\section{All Aortic-Valve Replacements}

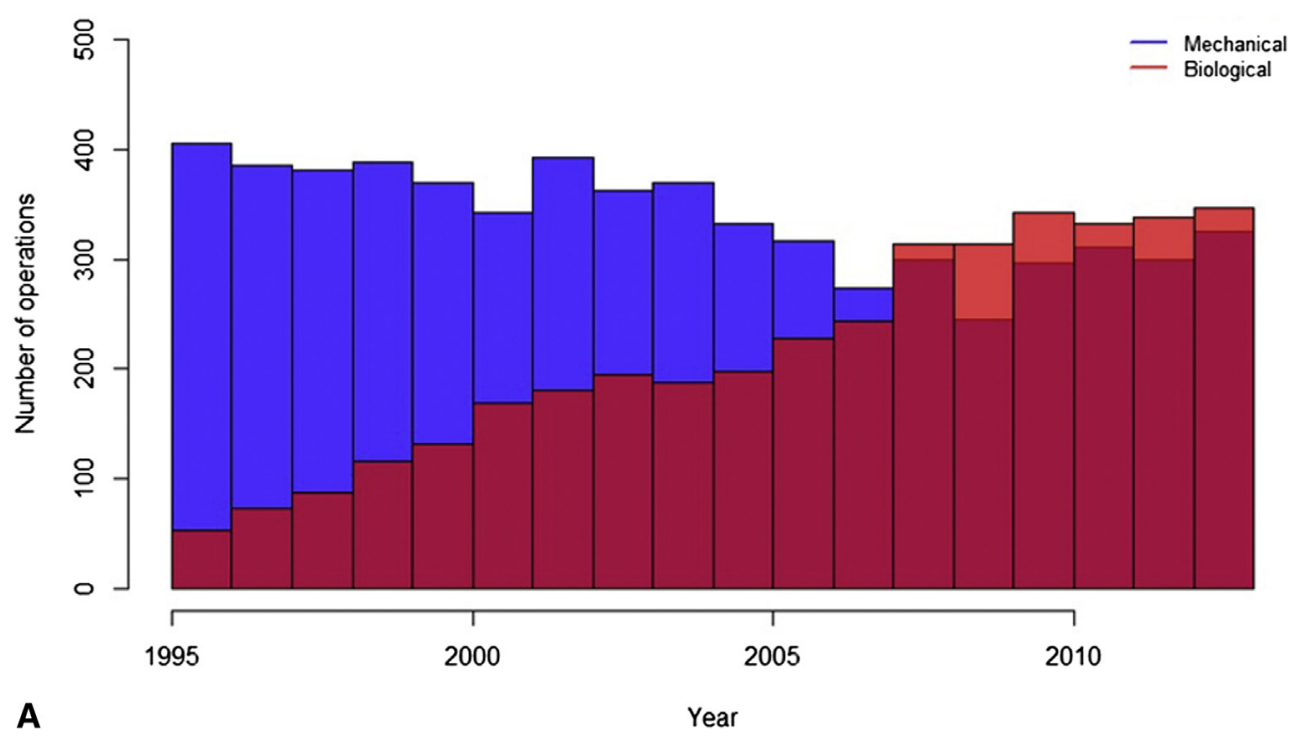

All Mitral-Valve Replacements

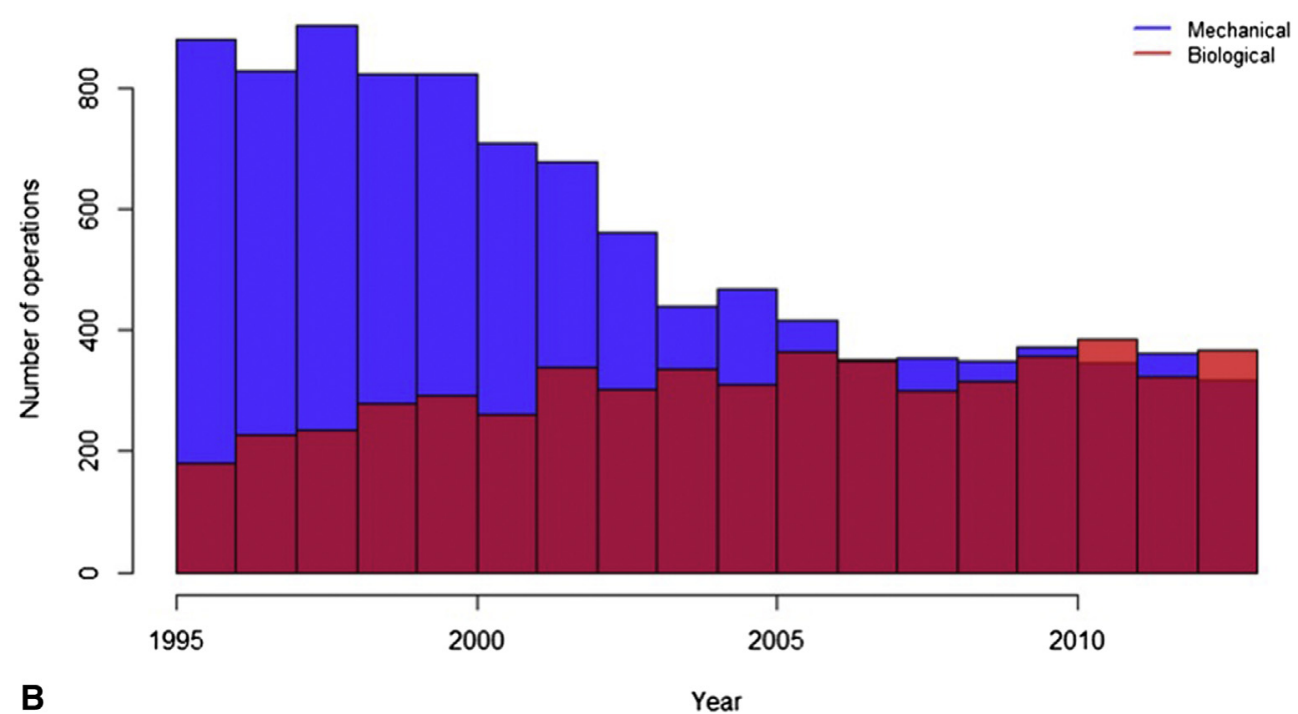

FIGURE 1. Change in prosthesis type implantation over time in the (A) aortic and (B) mitral valve positions. From Goldstone, Chiu, and colleagues. ${ }^{11}$ Copyright (C) 2017 Massachusetts Medical Society. Reprinted with permission.

One of the earliest attempts to use modern statistical methods to create a head-to-head comparison between biologic and mechanical valve prostheses was by Brown and colleagues ${ }^{17}$ from the Mayo Clinic comparing matched patients between 50 and 70 years of age receiving biologic or mechanical aortic valve prostheses. The investigators found that patients receiving a mechanical aortic valve had superior mid-term survival. However, there was a statistically significant difference in the risk of perioperative mortality (mechanical vs biologic prosthesis: $1.8 \%$ vs $5.5 \%$,
$P=.04)$, and there was no difference in freedom from reoperation between mechanical and biologic prostheses at 10 years: $97.5 \%$ versus $91 \%(P=.1)$. These results with respect to perioperative mortality and reoperation were distinctly different from randomized data; whether the analysis was affected by selection bias is uncertain.

The 2014 guidelines further liberalized the prosthesis selection criteria and introduced a grey zone in which either valve was considered to be appropriate for patients 60 to 70 years of age (Table 1) ${ }^{18}$ This relaxation of the guideline 
represented a de facto endorsement of the ongoing trend toward performing more biologic valve prosthesis implantations in progressively younger patients for both the aortic and mitral valves.

Shortly thereafter, 3 landmark observational studies were published. The first of these was a propensity score-matched study featuring 1001 matched pairs undergoing aortic valve replacement with a mechanical or biologic valve prosthesis between 1997 and 2004. Using the Statewide Planning and Research Cooperative System from New York State, Chiang and colleagues ${ }^{9}$ reported that there was no difference in survival between mechanical and biologic valve prostheses among patients 50 to 70 years of age. This finding suggested that the benefit due to mechanical aortic valve prostheses ended before age 50 years in a contemporary cohort of patients. Expected differences existed between patients with respect to risk of reoperation favoring mechanical prostheses (hazard ratio [HR], 0.52; 95\% confidence interval [CI], 0.36-0.75), but there was also an increased risk of bleeding with mechanical prostheses (HR, 1.75; 95\% CI, 1.27-2.43).

This finding was countered by Glaser and colleagues, ${ }^{10}$ who used the Swedish Web-system for Enhancement and Development of Evidence-based care in Heart disease Evaluated According to Recommended Therapies register between 1997 and 2013 to compare 1099 propensitymatched pairs. Biologic prostheses had a significantly higher mortality than mechanical prostheses in patients 50 to 70 years of age (HR, 1.34; 95\% CI, 1.09-1.66; $P=.006)$. In a subgroup analysis, there was an increased hazard of mortality with biologic prosthesis implantation than mechanical prosthesis implantation among patients 50 to 59 years of age (HR, 1.67; 95\% CI, 1.06-2.61, $P=.03)$ with no difference in the hazard of mortality among patients 60 to 69 years of age (HR, $1.08 ; 95 \% \mathrm{CI}$, $0.85-1.36, P=.5)$. Similar to the report by Chiang and colleagues, ${ }^{9}$ there was an increased risk of reoperation associated with biologic prostheses (HR, 2.36; 95\% CI, 1.42$3.94 ; P=.001)$ and reduced risk for bleeding (HR, 0.49; $95 \% \mathrm{CI}, 0.34-0.70 ; P=.001) .{ }^{10}$

The discordant results found in these 2 large studies may have been due to differences in longevity-related diseases between the cohorts from Sweden and New York State with greater incidence of diabetes, hypertension, atrial fibrillation, heart failure, and chronic obstructive pulmonary disease observed in the latter group. Of note, 15-year survival was similar between the 2 cohorts with mechanical prostheses: $62 \%$ compared with 59\% in New York State and Sweden, respectively. In contrast, survival appeared to be different among patients undergoing biologic prosthesis implantation with $61 \%$ surviving at 15 years in New York State compared with 50\% surviving at 15 years in Sweden. ${ }^{9,10}$ Without a direct comparative study between the 2 populations, reasons for this difference remain speculative.

For mitral valve replacement, Chikwe and colleagues ${ }^{16}$ again used the Statewide Planning and Research Cooperative System database for New York to construct a propensity score-matched comparison consisting of 664 matched pairs undergoing mitral valve replacement between 1997 and 2004. The inference was similar to their aortic valve study, suggesting that there was no significant survival difference between biologic and mechanical valve prostheses in patients between 50 and 70 years old. Again, the risk of reoperation was lower for mechanical prostheses than biologic prostheses (HR, 0.59; 95\% CI, 0.37-0.94; $P=.03$ ), and the risk of bleeding was greater (HR, $1.50 ; 95 \% \mathrm{CI}, 1.05$ 2.16; $P=.03){ }^{16}$

Professional guidelines were once again amended to lower the age of clinical equipoise to 50 years in 2017, independent of valve position (Table 1). ${ }^{19}$ However, whether the inference to be drawn from these studies was clinical equipoise among patients as young as 50 years of age is uncertain. Propensity score matching was used in each of the 3 observational studies outlined with exclusion of more than half of the patients given the use of a 1:1 matching algorithm. This technique selected only those patients receiving mechanical valve prostheses who were similar to patients receiving biologic valve prostheses, and thus excluded all of the patients for whom biologic valve prosthesis may have been considered an inappropriate choice. That these results might not be generalizable to all patients undergoing valve surgery greatly undermines the use of these studies to extend the age of clinical equipoise in the valve guidelines.

\section{MOVING FORWARD WITH BIG DATA}

Our group subsequently used California's Office of Statewide Health Planning and Development database between 1996 and 2013 to examine the comparative effectiveness of mechanical and biologic valve prostheses in both the aortic and mitral positions. In this study, inverse probability weighting was used with stabilized weights to achieve appropriate balance without excluding any patients. This allowed for estimation of the effect of all patients receiving one valve type or the other, that is, the average treatment effect $^{20}$; this represents the most pertinent question when attempting to formulate guidelines.

Examining 9942 patients undergoing aortic valve replacement in the state of California, we demonstrated that those who underwent aortic valve replacement with a biologic prosthesis experienced an increased hazard of mortality up to age 55 years (among patients 45 to 54 years of age: $\mathrm{HR}$, 1.23 ; $95 \% \mathrm{CI}, 1.02-1.48, P=.03$; among patients 55 64 years of age: $\mathrm{HR}, 1.04 ; 95 \% \mathrm{CI}, 0.91-1.18 ; P=.60) .{ }^{11}$ The cumulative incidence of bleeding was less for patients receiving biologic prostheses, but the cumulative incidence of reoperation was greater. This finding to some extent 

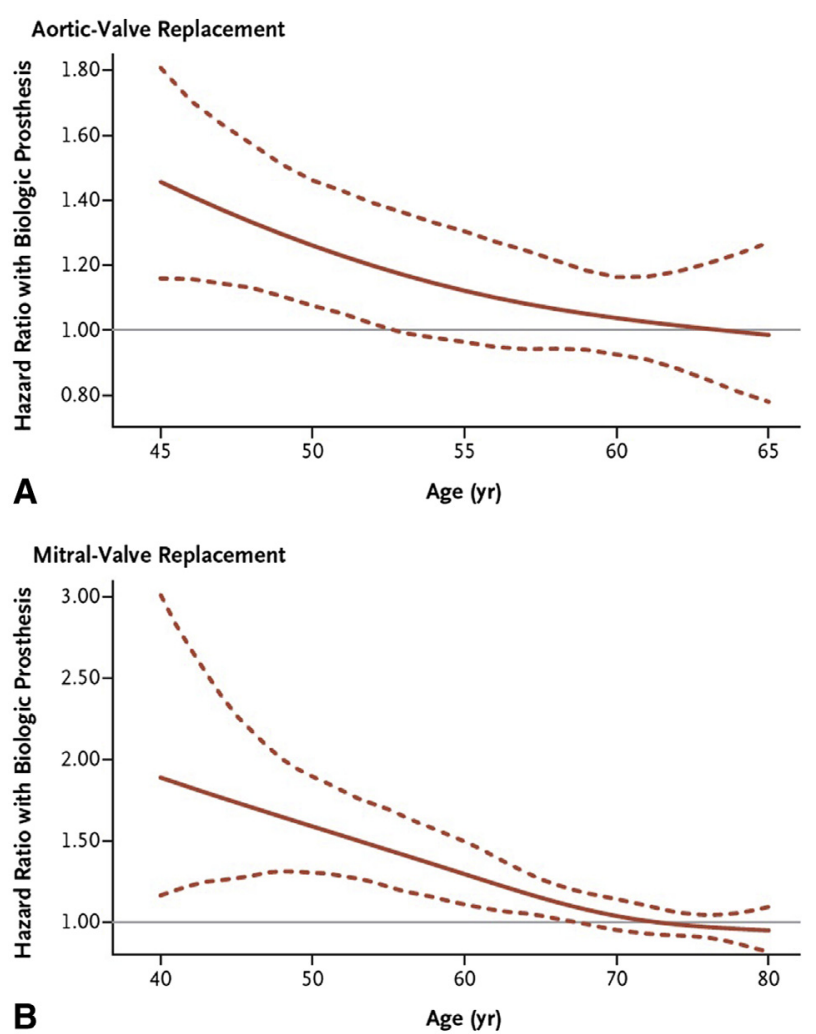

FIGURE 2. Age-dependent hazard of death with a biologic prosthesis compared with a mechanical prosthesis in the (A) aortic and (B) mitral valve positions. The HR for death is plotted among recipients of a biologic prosthesis, with mechanical valve as the reference group, evaluating age as a continuous variable (solid lines) with $95 \%$ CIs (dashed lines) obtained from bootstrap resampling. From Goldstone, Chiu, and colleagues. ${ }^{11}$ Copyright (c) 2017 Massachusetts Medical Society. Reprinted with permission.

validated the decrease in the lower limit of acceptable age for biologic prosthesis implantation. An exploratory analysis evaluating age as a continuous variable demonstrated that at approximately 53 years of age, the hazard of death associated with biologic valve prosthesis implantation in the aortic valve position disappeared (Figure 2, A).

We further examined 15,503 patients undergoing mitral valve replacement, and mortality was greater among patients receiving biologic valve prostheses compared with mechanical valve prostheses up to 70 years of age (HR, 1.16 ; $95 \%$ CI, $1.04-1.30 ; P=.01$, among patients 50 69 years of age). ${ }^{11}$ Similar to the aortic valve analysis, the cumulative incidence of bleeding was less, and the cumulative incidence of reoperation was greater with biologic valve prosthesis implantation. An exploratory analysis of age as a continuous variable suggested that the transition from increased hazard of mortality to equivalence between valve types occurred at approximately age 68 years (Figure 2, B). A reduction in the threshold for biologic valve implantation to 50 years of age in the guidelines may have been premature.

We must emphasize that our study, as well as the other population-based investigations, are observational and thus not randomized. Each study is subject to residual confounding owing to unmeasured variables. Unmeasured confounding is likely most severe at the extremes of agewhere equipoise is less likely to exist-and may explain the significant difference that we found in perioperative mortality after mitral valve replacement among patients 40 to 49 years old. However, unmeasured confounding would be expected to be less among patients who fall into the "grey area" in the guidelines, namely those 50 to 70 years of age, for which either valve type is deemed acceptable.

\section{REOPERATION AND DEVELOPMENT OF VALVE- IN-VALVE TECHNOLOGY: IMPLICATIONS ON BIOLOGIC VERSUS MECHANICAL VALVE PROSTHESIS SELECTION}

The primary disadvantage of biologic prostheses has been the risk for reoperation. Large single-center studies have reported the risk of perioperative mortality for reoperative aortic valve replacement to be as low as $2.5 \%$ to $5 \%{ }^{21-23}$ However, these results appear to be contradicted by population-based studies of aortic valve replacement with 30-day mortality after aortic valve reoperation being $9 \%$ in New York State and $7.1 \%$ in the state of California. ${ }^{9,11}$

These results are mirrored in the mitral position. Reoperative mitral valve surgery (either replacement after prior repair or repeat replacement) has been reported to have mortality ranging from $4.3 \%$ to $9 \%$ and potentially no different from first-time mitral valve replacement. ${ }^{24-26}$ However, reports from the Virginia Cardiac Services Quality Initiative and the state of California-less apt to be influenced by publication bias-revealed mortality for reoperative mitral valve surgery to be higher: between $11.1 \%$ and $14.0 \%$. $^{11,27}$

Given the substantial risk associated with reoperative surgery, transcatheter technologies offer the opportunity for valve replacement without redo sternotomy. A discussion of transcatheter valve-in-valve technologies has been included in the guidelines as an important part of the shared decision-making process in selecting a valve prosthesis. ${ }^{19}$ However, an important consideration is that the perioperative mortality observed with transcatheter valve-in-valve procedures remains high: $7.6 \%$ in the aortic position and $6.5 \%$ in the mitral position.

Beyond the risk of perioperative mortality, one of the difficulties inherent to valve-in-valve technology is the limitation introduced by the size of the patient and the surgically implanted valve prosthesis. In the aortic valve position, severe patient-prosthesis mismatch occurred in $31.8 \%$ of 
patients undergoing transcatheter aortic valve-in-valve procedures in the VIVID registry; $29.7 \%$ of patients in the registry had a labeled size $21 \mathrm{~mm}$ or smaller. ${ }^{28}$ Notably, between $34.2 \%$ and $41 \%$ of patients receive a surgical aortic valve that is less than $23 \mathrm{~mm}$ in size, and this limits the potential for subsequent valve-in-valve procedures because of the risk for patient-prosthesis mismatch. ${ }^{13,29,30}$ An additional $33 \%$ to $36 \%$ of patients receive a $23-\mathrm{mm}$ prosthesis, ${ }^{13,30}$ which still leaves the possibility for patient-prosthesis mismatch in the setting of valve-invalve procedures. ${ }^{31}$ To avoid this issue in valve-in-valve procedures, the practice of purposely fracturing the surgical valve has been shown to be a viable option. ${ }^{32}$ However, long-term results for this practice have not been published.

Aortic root enlargement may be an attractive option for implanting a large enough biologic valve to accommodate future valve-in-valve reoperations in young patients. David and colleagues, at the University of Toronto, have reported performing aortic root enlargements in $19 \%$ to $26 \%$ of patients undergoing biologic aortic valve prosthesis implantation. ${ }^{12,33}$ Despite reports emerging from centers of excellence demonstrating that aortic root enlargement may be performed with no additional risk of mortality ${ }^{34,35}$ the lack of a difference may be in part due to publication bias given the significant relationship between volume and outcome in proximal aortic operations. ${ }^{36}$ Relying on routine aortic root enlargement to implant biologic valve prostheses large enough to accommodate subsequent valve-in-valve procedures may not be a tenable strategy for most surgeons, and the implantation of mechanical aortic valves remains a relevant strategy for patients younger than 55 years of age.

Given the high risk associated with reoperative mitral valve surgery seen in both the Virginia Cardiac Services Quality Initiative and our report from the state of California, mitral valve-in-valve as a means of treating structural valve deterioration is an attractive option and ostensibly a reason to favor biologic over mechanical valve prostheses. Results from the Transcatheter Mitral Valve Replacement multicenter registry have demonstrated low 30-day mortality $(6.5 \%)$ for both valve-in-valve and valve-in-ring procedures. Despite the low periprocedural mortality, these technologies, although technically feasible, still require refinement. Device success, using a modification of the Mitral Valve Academic Research Consortium criteria, ${ }^{37}$ was only $89.2 \%$ for valve-in-valve. ${ }^{38}$ Furthermore, given the challenges related to approach (transatrial, transapical, or transseptal) and the potential for left ventricular outflow tract obstruction, eligibility for transcatheter valve-in-valve procedures may be lower in failing biologic mitral valve prostheses than for failing biologic prostheses in the aortic position. As such, whether surgeons and patients can rely on this technology as a routine solution to structural valve deterioration of biologic mitral valve prostheses in the near future is uncertain, and these data support the use of mechanical mitral valve prostheses in younger patients.

With the reduced success rate-a mere $76.4 \%$ - seen with valve-in-ring, the cost of a failed repair is amplified as transcatheter valve-in-ring may not serve as an adequate bail-out for early or mid-term failure of a repair. The success of mitral valve repair appears related to surgeon and institutional experience. Population-level investigations in New York State and Virginia revealed that high-volume surgeons repaired between $73 \%$ and $77 \%$ of all mitral valves compared with $26 \%$ to $48 \%$ for surgeons performing fewer operations. ${ }^{39,40}$ Furthermore, reference centers have reported approximately $100 \%$ repair rates in degenerative disease with excellent outcomes at midterm follow-up. ${ }^{41-43}$ With the variability in success, discussing mitral valve repair with a young patient will necessarily include a discussion of mitral valve replacement with a mechanical valve prosthesis as a contingency plan unless the patient is willing to accept the increased risk of reoperation and mortality associated with a biologic valve prosthesis. With even a slight chance of replacement, referral to a reference center may be preferable.

Without a doubt, technologic improvements will further reduce the risk associated with transcatheter valve-invalve procedures as has been seen with first-time transcatheter aortic valve replacement. Indeed, the recently published results of the PARTNER 3 trial showing a lower rate of the composite outcome of death, stroke, and rehospitalization for transcatheter aortic valve replacement as compared with surgical aortic valve replacement adds yet another dimension to the discussion of aortic valve prosthesis selection. ${ }^{44}$ However, questions regarding durability remain. At this time, transcatheter technology has yet to demonstrate adequate long-term outcomes to reliably serve as the standard approach for either first-time aortic valve replacement in young patients expected to require a second procedure or reoperative valve replacement for structural valve deterioration of biologic aortic or mitral valve prostheses. Furthermore, with the added risk of mortality at the time of reoperation-and possibly second reoperation for selected patients-it remains to be seen whether this approach will adequately mitigate the reoperative risk to render biologic prosthesis implantation equivalent to mechanical valve replacement in young patients. This will remain an area of active inquiry with the transcatheter revolution.

\section{CONCLUSIONS}

The guidelines for prosthesis choice in valve replacement have evolved considerably from the early recommendations becoming progressively more liberal with the merging of the recommendations for mitral and aortic valve prostheses and the introduction - and progressive widening — of a grey zone in which either valve is considered reasonable. The 
most recent observational evidence suggests that although more liberal use of biologic prostheses in younger patients may be appropriate for the aortic valve, the support for this practice in the mitral position is not as strong. The enthusiasm for biologic valve implantation in the mitral position for young patients should be tempered. As transcatheter technologies continue to develop, the risks-benefit tradeoff between biologic and mechanical valves will evolve. However, until procedural safety and long-term durability are proven, reliance on these technologies as a routine salvage procedure may be overly optimistic.

\section{Conflict of Interest Statement}

Authors have nothing to disclose with regard to commercial support.

\section{References}

1. Bloomfield P, Wheatley DJ, Prescott RJ, Miller HC. Twelve-year comparison of a Bjork-Shiley mechanical heart valve with porcine bioprostheses. $N$ Engl J Med. 1991;324:573-9.

2. Hammermeister KE, Sethi GK, Henderson WG, Oprian C, Kim T, Rahimtoola S. A comparison of outcomes in men 11 years after heart-valve replacement with a mechanical valve or bioprosthesis. Veterans affairs cooperative study on valvular heart disease. N Engl J Med. 1993;328:1289-96.

3. Cohn LH, Collins JJ Jr, DiSesa VJ, Couper GS, Peigh PS, Kowalker W, et al. Fifteen-year experience with 1678 Hancock porcine bioprosthetic heart valve replacements. Ann Surg. 1989;210:435-43.

4. Burdon TA, Miller DC, Oyer PE, Mitchell RS, Stinson EB, Starnes VA, et al. Durability of porcine valves at fifteen years in a representative North American patient population. J Thorac Cardiovasc Surg. 1992;103:238-52.

5. ACC/AHA guidelines for the management of patients with valvular heart disease. A report of the American College of Cardiology/American Heart Association. Task force on practice guidelines (Committee on management of patients with valvular heart disease). J Am Coll Cardiol. 1998;32:1486-588.

6. Hammermeister K, Sethi GK, Henderson WG, Grover FL, Oprian C, Rahimtoola SH. Outcomes 15 years after valve replacement with a mechanical versus a bioprosthetic valve: final report of the veterans affairs randomized trial. J Am Coll Cardiol. 2000;36:1152-8.

7. Oxenham H, Bloomfield P, Wheatley DJ, Lee RJ, Cunningham J, Prescott RJ, et al. Twenty year comparison of a Bjork-Shiley mechanical heart valve with porcine bioprostheses. Heart. 2003;89:715-21.

8. American College of Cardiology, American Heart Association Task Force on Practice Group, Society of Cardiovascular Association, Bonow RO, Carabello BA, Chatterjee K, et al. ACC/AHA 2006 guidelines for the management of patients with valvular heart disease: a report of the American College of Cardiology/American Heart Association task force on practice guidelines (writing committee to Revise the 1998 guidelines for the management of patients with valvular heart disease) developed in collaboration with the Society of Cardiovascular Anesthesiologists endorsed by the Society for Cardiovascular Angiography and Interventions and the Society of Thoracic Surgeons. J Am Coll Cardiol. 2006;48:e1-148.

9. Chiang YP, Chikwe J, Moskowitz AJ, Itagaki S, Adams DH, Egorova NN. Survival and long-term outcomes following bioprosthetic vs mechanical aortic valve replacement in patients aged 50 to 69 years. JAMA. 2014;312:1323-9.

10. Glaser N, Jackson V, Holzmann MJ, Franco-Cereceda A, Sartipy U. Aortic valve replacement with mechanical vs. biological prostheses in patients aged 50-69 years. Eur Heart J. 2016;37:2658-67.

11. Goldstone AB, Chiu P, Baiocchi M, Lingala B, Patrick WL, Fischbein MP, et al. Mechanical or biologic prostheses for aortic-valve and mitral-valve replacement. N Engl J Med. 2017;377:1847-57.

12. David TE, Armstrong S, Maganti M. Hancock II bioprosthesis for aortic valve replacement: the gold standard of bioprosthetic valves durability? Ann Thorac Surg. 2010;90:775-81.
13. Johnston DR, Soltesz EG, Vakil N, Rajeswaran J, Roselli EE, Sabik JF III, et al. Long-term durability of bioprosthetic aortic valves: implications from 12,569 implants. Ann Thorac Surg. 2015;99:1239-47.

14. Stassano P, Di Tommaso L, Monaco M, Iorio F, Pepino P, Spampinato N, et al. Aortic valve replacement: a prospective randomized evaluation of mechanical versus biological valves in patients ages 55 to 70 years. J Am Coll Cardiol. 2009;54:1862-8.

15. Eric Jamieson WR, Marchand MA, Pelletier CL, Norton R, Pellerin M, Dubiel TW, et al. Structural valve deterioration in mitral replacement surgery: comparison of Carpentier-Edwards supra-annular porcine and Perimount pericardial bioprostheses. J Thorac Cardiovasc Surg. 1999;118:297-304.

16. Chikwe J, Chiang YP, Egorova NN, Itagaki S, Adams DH. Survival and outcomes following bioprosthetic vs mechanical mitral valve replacement in patients aged 50 to 69 years. JAMA. 2015;313:1435-42.

17. Brown ML, Schaff HV, Lahr BD, Mullany CJ, Sundt TM, Dearani JA, et al. Aortic valve replacement in patients aged 50 to 70 years: improved outcome with mechanical versus biologic prostheses. J Thorac Cardiovasc Surg. 2008; 135:878-84.

18. Nishimura RA, Otto CM, Bonow RO, Carabello BA, Erwin JP III, Guyton RA, et al. 2014 AHA/ACC guideline for the management of patients with valvular heart disease: a report of the American College of Cardiology/American Heart Association task force on practice guidelines. J Am Coll Cardiol. 2014;63:e57-185.

19. Nishimura RA, Otto CM, Bonow RO, Carabello BA, Erwin JP 3rd, Fleisher LA, et al. 2017 AHA/ACC focused update of the 2014 AHA/ACC guideline for the management of patients with valvular heart disease: A report of the American College of Cardiology/American Heart Association task force on clinical practice guidelines. J Am Coll Cardiol. 2017;70:252-89.

20. Stuart EA. Matching methods for causal inference: a review and a look forward. Stat Sci. 2010;25:1-21.

21. Potter DD, Sundt TM III, Zehr KJ, Dearani JA, Daly RC, Mullany CJ, et al. Operative risk of reoperative aortic valve replacement. J Thorac Cardiovasc Surg. 2005;129:94-103.

22. Leontyev S, Borger MA, Davierwala P, Walther T, Lehmann S, Kempfert J, et al. Redo aortic valve surgery: early and late outcomes. Ann Thorac Surg. 2011;91: 1120-6.

23. Naji P, Griffin BP, Sabik JF, Kusunose K, Asfahan F, Popovic ZB, et al. Characteristics and outcomes of patients with severe bioprosthetic aortic valve stenosis undergoing redo surgical aortic valve replacement. Circulation. 2015;132:1953-60.

24. Borger MA, Yau TM, Rao V, Scully HE, David TE. Reoperative mitral valve replacement: importance of preservation of the subvalvular apparatus. Ann Thorac Surg. 2002;74:1482-7.

25. Dumont E, Gillinov AM, Blackstone EH, Sabik JF III, Svensson LG, Mihaljevic T, et al. Reoperation after mitral valve repair for degenerative disease. Ann Thorac Surg. 2007;84:444-50.

26. Exposito V, Garcia-Camarero T, Bernal JM, Arnaiz E, Sarralde A, Garcia I, et al. Repeat mitral valve replacement: 30-years' experience. Rev Esp Cardiol. 2009; 62:929-32.

27. Mehaffey HJ, Hawkins RB, Schubert S, Fonner C, Yarboro LT, Quader M, et al. Contemporary outcomes in reoperative mitral valve surgery. Heart. 2018;104: 652-6.

28. Dvir D, Webb JG. Transcatheter aortic valve-in-valve implantation for patients with degenerative surgical bioprosthetic valves. Circ J. 2015;79:695-703.

29. Brennan JM, Edwards FH, Zhao Y, O'Brien S, Booth ME, Dokholyan RS, et al. Long-term safety and effectiveness of mechanical versus biologic aortic valve prostheses in older patients: results from the Society of Thoracic Surgeons Adult Cardiac Surgery National Database. Circulation. 2013;127:1647-55.

30. Reardon MJ, Van Mieghem NM, Popma JJ. Surgical or transcatheter aortic-valve replacement. N Engl J Med. 2017;377:197-8.

31. Seiffert M, Conradi L, Baldus S, Knap M, Schirmer J, Franzen O, et al. Impact of patient-prosthesis mismatch after transcatheter aortic valve-invalve implantation in degenerated bioprostheses. J Thorac Cardiovasc Surg. 2012;143:617-24.

32. Chhatriwalla AK, Allen KB, Saxon JT, Cohen DJ, Aggarwal S, Hart AJ, et al. Bioprosthetic valve fracture improves the hemodynamic results of valve-invalve transcatheter aortic valve replacement. Circ Cardiovasc Interv. 2017;10.

33. Une D, Ruel M, David TE. Twenty-year durability of the aortic Hancock II bioprosthesis in young patients: is it durable enough? Eur J Cardiothorac Surg. 2014;46:825-30.

34. Rocha RV, Manlhiot C, Feindel CM, Yau TM, Mueller B, David TE, et al. Surgical enlargement of the aortic root does not increase the operative risk of aortic valve replacement. Circulation. 2018;137:1585-94. 
35. Dhareshwar J, Sundt TM III, Dearani JA, Schaff HV, Cook DJ, Orszulak TA. Aortic root enlargement: what are the operative risks? J Thorac Cardiovasc Surg. 2007;134:916-24.

36. Hughes GC, Zhao Y, Rankin JS, Scarborough JE, O'Brien S, Bavaria JE, et al. Effects of institutional volumes on operative outcomes for aortic root replacement in North America. J Thorac Cardiovasc Surg. 2013:145:166-70.

37. Stone GW, Adams DH, Abraham WT, Kappetein AP, Genereux P, Vranckx P, et al. Clinical trial design principles and endpoint definitions for transcatheter mitral valve repair and replacement: Part 2: endpoint definitions: a consensus document from the mitral valve academic research consortium. J Am Coll Cardiol. 2015;66:308-21.

38. Yoon SH, Whisenant BK, Bleiziffer S, Delgado V, Schofer N, Eschenbach L, et al. Transcatheter mitral valve replacement for degenerated bioprosthetic valves and failed annuloplasty rings. J Am Coll Cardiol. 2017;70:1121-31.

39. LaPar DJ, Ailawadi G, Isbell JM, Crosby IK, Kern JA, Rich JB, et al. Mitral valve repair rates correlate with surgeon and institutional experience. J Thorac Cardiovasc Surg. 2014;148:995-1004.

40. Chikwe J, Toyoda N, Anyanwu AC, Itagaki S, Egorova NN, Boateng P, et al. Relation of mitral valve surgery volume to repair rate, durability, and survival. J Am Coll Cardiol. April 24, 2017 [Epub ahead of print].
41. Castillo JG, Anyanwu AC, Fuster V, Adams DH. A near 100\% repair rate for mitral valve prolapse is achievable in a reference center: implications for future guidelines. J Thorac Cardiovasc Surg. 2012;144:308-12.

42. Goldstone AB, Cohen JE, Howard JL, Edwards BB, Acker AL, Hiesinger W, et al. A "repair-all" strategy for degenerative mitral valve disease safely minimizes unnecessary replacement. Ann Thorac Surg. 2015;99:1983-91.

43. Lawrie GM, Zoghbi W, Little S, Shah D, Ben-Zekry Z, Earle N, et al. One hundred percent reparability of degenerative mitral regurgitation: intermediate-term results of a dynamic engineered approach. Ann Thorac Surg. 2016;101:576-84.

44. Mack MJ, Leon MB, Thourani VH, Makkar R, Kodali SK, Russo M, et al. Trans catheter aortic-valve replacement with a balloon-expandable Valve in low-risk patients. N Engl J Med. 2019;380:1695-705.

45. Bonow RO, Carabello BA, Chatterjee K, de Leon AC Jr, Faxon DP, Freed MD, et al. 2008 focused update incorporated into the ACC/AHA 2006 guidelines for the management of patients with valvular heart disease: a report of the American College of Cardiology/American Heart Association Task Force on Practice Guidelines (Writing Committee to Revise the 1998 Guidelines for the Management of Patients With Valvular Heart Disease): endorsed by the Society of Cardiovascular Anesthesiologists, Society for Cardiovascular Angiography and Interventions, and Society of Thoracic Surgeons. Circulation. 2008;118: e523-661. 